\title{
The Relevance of Digital Sharing Business Models for Sustainability
}

\author{
Maria J. Pouri ${ }^{\dagger}$ \\ Department of Informatics \\ University of Zurich \\ Zurich, Switzerland \\ pouri@ifi.uzh.ch
}

\author{
Lorenz M. Hilty \\ Department of Informatics \\ University of Zurich \\ Zurich, Switzerland \\ hilty@ifi.uzh.ch
}

\begin{abstract}
There is a growing discussion about the "Digital Sharing Economy" (DSE). The pervasiveness of digital platforms and the growing interest in a sharing (rather than ownership) style of consumption have allowed for sharing practices to scale up and become a widespread phenomenon. Digital sharing platforms offer a wide variety of services which appear to be more affordable, efficient, and accessible than their conventional counterparts, making them more attractive in the eyes of consumers. The DSE has manifested itself most remarkably in consumer-to-consumer (C2C) and business-to-consumer (B2C) sharing models. New business models have been created to capture and offer the values driving the emerging sharing trend.
\end{abstract}

The innovative, digitally enabled mode of providing access to resources as a service in the DSE has changed consumption patterns both at micro level, as a change in individual lifestyles, and at macro level, manifested in a transformation of socio-economic structures. These ongoing changes may have both positive and negative implications for society from a sustainability perspective. Recognising that the (potential and actual) impacts of sharing platforms on sustainability have not been studied in a systematic way yet, the present paper aims to develop a systematic insight into this interaction by focusing on the business models emerging around sharing platforms as a central starting point. To achieve this, we use a typology of business models that recognizes the affordances and key attributes of sharing in the DSE. The typology covers both $\mathrm{C} 2 \mathrm{C}$ and $\mathrm{B} 2 \mathrm{C}$ models of sharing. Based on this typology, we discuss the implications of each type of sharing model for sustainability by asking two central questions: How may the given type of sharing affect resource consumption? And what will be the potential impacts on social practices and structures? We hope that the present study can serve as a guideline for assessing the

${ }^{\dagger}$ Corresponding Author

Permission to make digital or hard copies of part or all of this work for personal or classroom use is granted without fee provided that copies are not made or distributed for profit or commercial advantage and that copies bear this notice and the full citation on the first page. Copyrights for third-party components of this work must be honored. For all other uses, contact the Owner/Author.

ICT4S2020, June 21-26, 2020, Bristol, United Kingdom

C2020 Copyright is held by the owner/author(s).

ACM ISBN 978-1-4503-7595-5/20/06.

https://doi.org/10.1145/3401335.3401344 sustainability impacts of sharing platforms - either already operating in the market or envisaged. By highlighting the aspects most relevant from a sustainability point of view, we expect to contribute to an evolution of the DSE business models towards sustainable development.

\section{CCS CONCEPTS}

- Information Systems $\rightarrow$ Information systems applications $\rightarrow$ Collaborative and social computing systems and tools $\bullet$ Social and Professional Topics $\rightarrow$ Professional topics $\rightarrow$ Computing and business $\rightarrow$ Economic impact $\bullet$ Social and Professional Topics $\rightarrow$ Professional topics $\rightarrow$ Computing and business $\rightarrow$ Socio-technical Systems •

\section{KEYWORDS}

Information and communication technology (ICT), Digital sharing economy, Sharing business models, Sharing platforms, Sustainability impacts, Resource consumption, Socio-economic structures

\section{ACM Reference format:}

Maria J. Pouri and Lorenz M. Hilty. 2020. The Relevance of Digital Sharing Business Models for Sustainability. In Proceedings of the 7th International Conference on ICT for Sustainability (ICT4S 2020). ACM, New York, NY, USA, 11 pages. https://doi.org/10.1145/3401335.3401344

\section{INTRODUCTION}

The "Digital Sharing Economy" (DSE) [1] has changed patterns of consumption by introducing new choices and channels for the provision and receipt of services. It can be viewed as a new use case of Information and Communication Technology (ICT), a use case which could play a significant role in the necessary transformation towards sustainability. Most importantly, in its Consumer-toConsumer (C2C) models, the DSE has created a new culture of sharing [2, 3] whereby individuals engage with different motivations for sharing. Individuals collaborate with their peers in organising access to resources rather than being purely dependent on services from businesses in the conventional market (also called "pipeline businesses" [4, 5]) [1]. In addition, Business-toConsumer (B2C) sharing models have appeared to be offering more 
affordable services compared to those provided via the pipeline businesses that have "dominated industry for decades" [5, p. 4].

The emergence and proliferation of digital platforms as intermediaries for sharing $[2,6,7]$ has led to the DSE catching many consumers in the mainstream segment - making the DSE primarily a mainstream phenomenon [8] - in an unprecedented way [9-11]. Both applause and concerns about the DSE's alignment with sustainability objectives have been raised [12-14].

The widespread popularity of digitally enabled sharing is known to have originated from recent leaps in social technologies and shifts in social attitudes [2]. Some authors relate the current scale and growth of the DSE to developments in ICT and the proliferation of collaborative web-based communities that focus on user-generated contents required for conducting social commerce and practicing social sharing [6]. In another work [15], the authors conceptualized the DSE as a by-product of digitalization whereby the phenomenon became possible in line with "the digital transition of sharing" that removed the constraints of time, place, participation, communication, and coordination of traditional sharing. Sharing practices that were traditionally restricted to small groups (such as family and friends) have been transformed and scaled up by digital platforms. To describe this recent phenomenon, an extended concept of sharing that goes beyond the traditional notion of sharing is needed. The extended concept we are proposing subsumes both the social and the technical meaning of "sharing". The technical notion of sharing has been in use for a long time as well, e.g. in "shared space", "shared capacity", etc. The discourse of the DSE seems to be partially built on the ambiguity of the term "sharing" arising due the unclarified coexistence of its technical and social meaning in parallel. By introducing the extended concept [15], we resolve this ambiguity by being more comprehensive. Using the extended concept provides the opportunity to make explicit, systematic and fine-grained distinctions among different types of digital sharing - distinctions that matter from a sustainability point of view and that can be analysed without bias. This distinguishes our approach from the position of some authors who advocate for a much narrower concept of sharing - and consequently divide the phenomena observed in the DSE in "(true) sharing" and "pseudo sharing". In our view, there is no "pseudo sharing", there are just amazingly different forms of sharing.

The DSE, as defined by the authors [15], is "A class of resource allocation systems based on sharing practices which are coordinated by digital online platforms and performed by individuals and possibly (non-) commercial organizations with the aim to provide access to material and immaterial resources. Digital sharing systems operate in the space between traditional sharing and the formal economy."

Regarding sustainability, we refer to the original Brundtland definition, which defines sustainable development as "development that meets the needs of the present without compromising the ability of future generations to meet their own needs" [16]. We are aware of the variety of frameworks that are based on the so-called "three pillars" or "dimensions" of sustainability (namely the social, environmental, and economic dimension), including the triple bottom line approach ("People, Planet, Profit"). We intentionally do not use these frameworks because they suggest an ontology in which the economic system seems to exist outside society, and human society outside nature.

In contrast to this, we regard the economic system as a part of human society and human society as a part of the biosphere. From this point of view, the sustainability of an action is determined by two types of interaction: First, the interaction between technosphere and the biosphere, i.e. the use of natural resources and ecosystem services (where the latter can also be subsumed under resources in the broader sense of the term). Second, the interaction between humans, including social practices of giving others access to resources.

This conceptualization accords with Raworth's "Doughnut model" in which the idea of planetary and social boundaries are combined into a common framework. Sustainable development, then, has to ensure that "the needs of people are met without overshooting Earth's ecological ceiling." [17].

Throughout this paper, we focus on describing the DSE and its business models (BMs) from two perspectives that focus on the aspects of the DSE that are most relevant for sustainability: the resource perspective and the socio-economic perspective.

To figure out the relevance of the DSE for sustainability in the sense described above, we use the business model concept as a link between the DSE context and the sustainability context. BMs are of practical and economic importance [18]. Although BMs have been usually studied in the context of commercial enterprises, their concept can be applied as well to a variety of non-commercial enterprises, governance models, and initiatives such as social innovation [19-21] - wherein the DSE has root [22]. The BM concept holds promise for applications in contexts relevant to sustainability and actions towards sustainable development [2325].

The aim of the present study is to explore the implications of business models BMs in the DSE (as defined above) for sustainability with respect to resource consumption and social practices. Our focus will be on $\mathrm{C} 2 \mathrm{C}$ and $\mathrm{B} 2 \mathrm{C}$ sharing business models (also discussed as "peer-to-peer intermediation" and "centralized resource pooling", respectively [20]) because of the popularity of their services. The rest of this work is structured as follows: Section 2 presents an overview of the current literature on BMs in the DSE and on their relevance for sustainability. Section 3 describes the method of the qualitive analysis, which is then applied in Section 4. After discussing the impacts in terms of opportunities and risks for sustainability in Section 5, the paper closes with conclusions and an outlook. 


\section{RELATED WORK}

In a broad sense, there are two pivotal contexts of change in which BMs in the DSE are studied:

1) increasing diffusion of digital sharing BMs, and

2) their relevance for sustainability [26].

There has been an expansion of sharing activities in recent years $[6,11,27]$, leading to the DSE facing a phenomenal growth [28, 29]. The popularity of sharing services has been explained by the shift of consumers' mindset which is determined by their satisfaction with sharing services and their intention to use them [30]. It has also been attributed to a shift of values and motivations [31] towards services that are widely accessible and reliable, that generate savings for consumers, and that offer proven utility [30]. Platforms offer a wide variety of services which are typically more affordable, efficient, convenient, and accessible than their counterparts in the conventional market.

Sharing seems to provide greater value in accessing resources rather than owning them for consumers [32, 33]. Access to resources can immediately and directly become possible for consumers upon need; a process which is heavily endorsed by ICT applications and digital platforms [6]. Moreover, individuals with different motivations engage in sharing; motivations such as willingness to maintain social interactions, gaining economic benefits, the intent to protect the environment as well as altruistic and community-oriented values [2, 34-36]. Around these values, sharing BMs evolve [20]. Since BMs support the provision of value to customers [37], from a BM perspective, what matters is to see how sharing platforms create value, and how this value is perceived and offered across sharing systems [20].

The DSE combines both market and non-market logics for creating and capturing sharing values [20]. Its BMs, therefore, can be based on different value (co-)creation logics ranging from pure economic benefits to pure pro-social motivations, i.e. moral motivations for the good of others and society at large based on normative principles. It is posited that the DSE operates in and across the space between traditional sharing and formal markets, and can generate non-monetary or monetary values for its participants [15]. This not only opens a wide space for potential digital sharing BMs, but also reveals opportunities and risks when interpreted in the context of sustainability [38].

In connection with sustainability, at a micro level, changes in sharing practices imply changes in consumption patterns because consumers will have new choices and may change their behaviour and lifestyle. The potential to change consumption patterns can be seen as an enabling effect of digital platforms with potential sustainability impacts $[1,39]$. The enabling effects, if prolonged enough, will cause transformative changes in social and economic structures at the macro level [40]. Therefore, it is important to see how the consumption patterns promoted by new trends of sharing may relate to sustainability goals.

While studies on BMs in the context of the DSE often focus on the BM of a particular sharing platform (e.g. [41] for Uber and [42] for Airbnb), the extant literature is quite proliferating in the intersection of the DSE and sustainability [e.g. 1, 12-15, 36, 39, 43, 44]. In general, two opposing positions are represented in the discourse, which could be called the "utopian" and the "dystopian" position: Some authors view digital sharing as "a potential new pathway to sustainability" [13]; others argue that it "extends harsh free-market practices into previously protected areas of our lives, and presents the opportunity for a few people to make fortunes by damaging communities and pushing vulnerable individuals to take on unsustainable risk." [45].

Daunorienė et al. [46] present an approach on how to address and evaluate the sustainability of sharing economy BMs based on the social, economic, environmental, and technological sustainability drivers of the DSE. Towards a more specific direction, Ciulli and Kolk [26] focus on how incumbents can change their existing BMs to embrace and affect the DSE from a sustainability perspective. They do so by "considering how different incumbent approaches to the sharing economy may have different, and sometimes mixed, implications for environmental, social and/or economic value creation." [26, p. 1007]. By developing a typology for sharing economy platforms, Acquier at al. [20] propose four possible configurations of sharing BMs (commonors, mission-driven, shared instrastructure provider, matchmakers) within which they study the sustainability impacts of sharing.

In [38], the authors declare 256 theoretical types of digital sharing systems based on the possible attribute values of their BM components. These components indicate the kind of resource providers, resource receivers, sharable resources, and sharing practices that eventually explain the motivations for sharing (i.e. the perceived values). Based on these components and their attribute values for a given platform, the sustainability impacts of that platform can be qualitatively assessed in a systematic way. From this wide spectrum, for the purpose of the present work, we narrow the focus to $\mathrm{C} 2 \mathrm{C}$ and $\mathrm{B} 2 \mathrm{C}$ platforms, while the approach can in principle be applied to all existing and conceivable platforms.

\section{METHODOLOGY}

For identifying those aspects of digital sharing systems which are essential for sustainability, we start from the two perspectives we introduced in Section 1:

1) the resource perspective whereby (shared) use of resources matters, and

2) the socio-economic perspective whereby the (potential) impacts of social and economic practices promoted by sharing platforms are questioned.

In the following, we elaborate on each perspective and the related approach to scan for aspects relevant for sustainability.

\subsection{Resource Perspective}

Shared consumption enabled by digital platforms seems to be saving resources at a first glance. However, to start with an 
unbiased perspective, we assume that the DSE in its various instances can have positive and negative effects on consumption patterns, and thus indirectly on the use of natural resources. To adopt the existing conceptual frameworks from the "ICT for Sustainability" field, we frame digital sharing as a special case of ICT infrastructure or application.

Existing literature presents various frameworks to reflect on the role of ICT in society's transition towards sustainability from a resource perspective (see [47]). An early framework in this area was proposed by Berkhout and Hertin [48], introducing the "threeorder of effects" model. This basic model was extended and further developed by many authors, including Dompke et al. [49] and Hilty and Aebischer [40]. We will build on the following four categories of effects, as a common core of previous approaches [40], to analyze the impacts of the DSE on sustainability from the resource perspective:

- Optimization effect: The use of ICT reduces the use of a resource by optimizing a process (e.g., less energy is used for heating in a smart home).

- Induction effect: ICT stimulates the consumption of another resource (e.g., a printer stimulates the consumption of paper).

- Substitution effect: The use of ICT replaces the use of another resource (e.g., the substitution of electronic media for print media).

- $\quad$ Rebound effect: The effect of increasing resource efficiency is compensated by an increase in demand, which offsets the possible savings partially or even entirely.

In addition to the above effects, we introduce the degradation effect which counteracts the optimization effect if resource use is optimized by maximizing the utilization of an asset: The more intense an asset is used, the faster it may degrade [50].

We propose to use these five categories of effects to qualitatively analyze the potential impacts of the DSE as a specific use case of ICT. Their relevance can be demonstrated using the typology of sharing BMs shown in Figure 1. For each type, we could ask the questions: Who has an interest in optimising the use of a resource (optimization effect) and what drives the counteracting degradation effect; what complementary consumption is induced by sharing (induction effect); what substitutions are taking place (substitution effect); and can the demand grow if the supply is efficient and convenient (rebound effect)?

It is obvious that some of these questions will yield different answers depending on, for example, the resource provider (individual or business), the motivation (for-profit or not-for profit), and whether existing resources are made accessible or investments are made to provide resources available for sharing. We will come back to these distinctions in the next section.

\subsection{Socio-economic Perspective}

From a socio-economic perspective, impacts on welfare and income, impacts on workers, impacts on social life and relationships, and impacts on equality $[43,51,52]$ are most discussed in the context of the DSE.

Given that the DSE subsumes different types of sharing systems with varying BMs targeting different mechanisms for value creation [20], we will study their socio-economic impacts qualitatively by classifying platforms and then identifying the socio-economic impacts most relevant to each type. To do so, we developed a typology based on an adaptation of the crucial elements of sharing BMs in [38]:

- resource provider (who shares),

- resource receiver (with whom to share),

- $\quad$ shared resource (what to share), and

- the motivation for sharing (why share).

This typology covers both $\mathrm{C} 2 \mathrm{C}$ and $\mathrm{B} 2 \mathrm{C}$ sharing models. Figure 1 shows a binary tree for the classification of $\mathrm{C} 2 \mathrm{C}$ and $\mathrm{B} 2 \mathrm{C}$ sharing systems from a business model perspective.

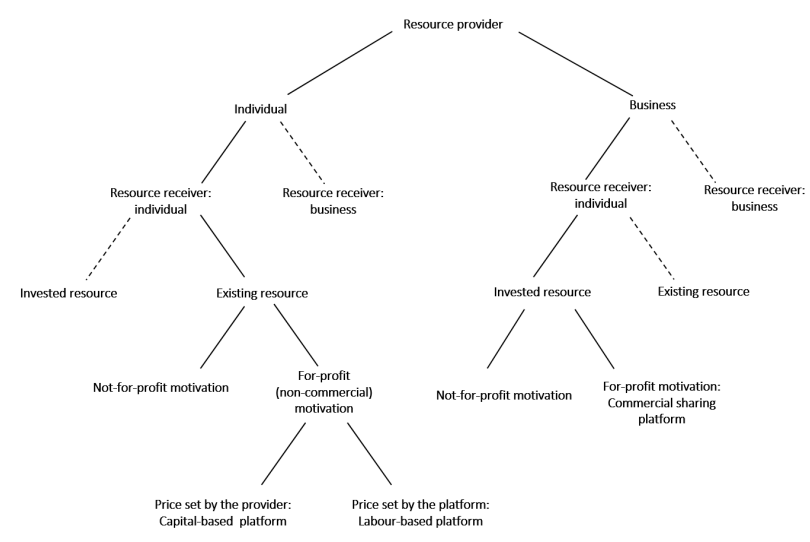

Figure 1: Classifying $\mathrm{C2C}$ and $\mathrm{B} 2 \mathrm{C}$ digital sharing business models based on the 'resource provider', 'resource receiver', 'provision of resource', and 'motivation for sharing' attributes.

The first level of the tree is about resource owners (the actors providing a resource for sharing); the second level refers to resource receivers. Since our focus is on $\mathrm{C} 2 \mathrm{C}$ and $\mathrm{B} 2 \mathrm{C}$, we did not unfold the classification for other models (C2B and $\mathrm{B} 2 \mathrm{C})$.

The third level is about the provision of durable material resources in a sharing system. By existing resource, we mean that the resource which is owned by a provider is already serving them, and upon entering into the sharing system, it will become accessible also to other receivers (shared use of a privately-owned asset). Invested resource refers to a status in which resources are provided to be used 'only' in a sharing system and are serving no other purpose for the owner. This type of provision is also called 'invested infrastructure' [20]. The invested provision mode is mostly implemented by commercial platforms and has important implications for resource consumption. Most relevantly, they can have implications for faster degradation of resources. The provision of existing resources is, however, more associated with $\mathrm{C} 2 \mathrm{C}$ 
models whereby individuals allow their peers to access/ use their owned assets.

It is notable that both types of provision can be assumed for both end-consumers and businesses. Nevertheless, we are excluding the $\mathrm{C} 2 \mathrm{C}$ types where the provider has invested resources and the $\mathrm{B} 2 \mathrm{C}$ types where the business shares its existing resources. It is not a common practice that an individual would invest a relatively high amount of money to buy a house, car etc. and then expect to gain good returns on investment by putting it into a sharing system to be used only by others. We are also excluding the case of existing resource provision in $\mathrm{B} 2 \mathrm{~B}$ models although it is currently a popular practice that businesses share their resources (infrastructure, human resource, etc.) with other businesses. This case is outside the focus of the present study, which is on sharing systems in which endconsumers (i.e. members of private households) are involved.

The forth level of the tree is about the primary motivation that drives sharing. Motivations for users' participation can be distinguished as follows: non-commercial economic motivations (i.e., individuals' for-profit motivations), commercial economic motivations (i.e., businesses' for-profit motivations), and not-forprofit motivations (applies to both individuals and businesses) [53].

The fifth level indicates the possible service owner (or the actor who sets prices for monetary-based sharing practices), resulting in two general types for for-profit $\mathrm{C} 2 \mathrm{C}$ platforms: labor-based platforms and capital-based platforms [54]. In labor-based models, such as Uber, prices are charged and controlled by the platform owner [52] while in the case of capital-based platforms, the resource provider sets the price.

The 5 leaves of the tree represent the prominent types of sharing business models whose sustainability impacts may substantially differ from a socio-economic perspective. In Section 4.2, we will qualitatively relate each of these types to their relevant sustainability impacts.

\section{ANALYSIS: SUSTAINABILITY-RELATED ASPECTS OF SHARING MODELS}

\subsection{Impacts on Resource Consumption}

4.1.1 Optimization Effect. Sharing platforms coordinate the distribution of idle and free capacity of existing resources to those who want to use them. When a resource is shared, its unproductive capacity comes into utilization to serve more demands. For example, when a person uses a carpooling service, more people (up to the capacity of the car) can ride the same car, and therefore the number of passenger kilometers the car will deliver per liter of fuel - and possibly even over the car's whole service life - will increase (increasing service load by occupying free capacity).

As the example shows, a 'functional unit' (as common in the methodology of Life Cycle Assessment, LCA) is needed to measure the service people receive from using the shared resource. In this case, the functional unit is 'passenger kilometer'. It is relevant to see how exactly the sharing practice creates the potential of maximizing the number of functional units produced per input of natural resources. For car sharing services such as Zipcar or ride services such as Uber's typical service, for example, the number of functional units can only increase over the service life of the car (because they do not serve multiple users/riders simultaneously). That is, when more people use the same car but not at the same time, the car can still produce more passenger kilometers over its entire lifetime because of reduced idle time. The idle time is the time when the car is not used, which will, however, involve some form of aging as well. A similar example is Botsman's case of the drill [55], which will be used more efficiently by being shared among a group of people instead of being used only for less than an hour in total throughout its entire lifetime by one user (the owner). Whereas in the case of cars, there are two technical options of sharing (activating idle time and occupying free capacity) which can optimize resource utilization. In other cases like the drill, activating idle time is the only option.

In either case, there is an optimization effect of sharing which is based on enhancing lifetime efficiency, defined as the total number of functional units delivered over the service life of a technical resource (which is connected to the inflow of natural resources needed to produce it, as can be determined by LCA methodology).

A different optimization effect can occur if the use of the technical resource is connected to the use of a complementary resource (such as energy) and the efficiency in using the complementary resource increases with sharing as well. To continue on the example of a car, increased load (as in the case of carpooling when free riding capacity is filled by sharing the ride) has the additional positive impact of needing less fuel per passenger kilometer. This is not the case for sharing models like Uber or Zipcar which only activate some idle capacity of a car.

4.1.2 Induction Effect. Any consumption, including the use of a shared resource, can be causally connected to the consumption of complementary resources, in most cases some form of energy. If this complementary consumption offsets parts of the resource saving intended with a sharing model, then we speak of induced consumption. For example, if the idle time of cars is partially activated by sharing, the use of street space by cars driving will increase. Space is, especially in urban areas, a scarce resource, and the necessary traffic infrastructures are produced with an enourmous investment of natural resources. Therefore, the occupation of street space is a complementary resource consumed when using a car, and this consumption can be induced by sharing models which activate idle time. For example, platforms like Uber and Lyft (another platform for ride services) are known to have deteriorated travel time reliability and to have increased traffic congestion [56], which in turn affects urban mobility, traffic safety, and environmental sustainability [57]. Obviously, induction effects must be taken into account when assessing the overall environmental effect of sharing schemes. To evaluate sharing models, we must look at the marginal consumption of the complementary resource per functional unit. If it decreases with the sharing model, sharing can still have a saving effect in terms of resources. 
4.1.3 Substitution Effect. It is important, yet demanding, to look at potential substitution effects of digital sharing from a perspective that includes the market outside the sharing system. Recalling the car example, studies indicate that car sharing services tend to reduce private car ownership by discouraging car purchases and substituting for private ownership [20]. It is claimed that every car sharing vehicle replaces 9 to 13 privately-owned vehicles [58]. However, it should be addressed that to what extent car sharing and ride services replace public transport, bike or scooter sharing schemes, or taxi services? This may highly depend on the local situation. With respect to lodging and homestay services, to mention another frequent example, it is relevant to see the extent to which Airbnb and Couchsurfing replace accommodation services offered by hostels, hotels, holiday apartments, traditional bed and breakfast schemes, or other types of accommodation. Substitution effects can have different implications for sustainability, depending on whether the new consumption patterns would substitute for higher or lower environmental impact options.

4.1.4 Rebound Effect. If any product or service becomes faster, cheaper or more convenient to access (as a result of efficient coordination, efficient access, and lower prices), a normal reaction of the market is an increase in the demand for that product or service. This may partly or fully balance out the possibly favorable impacts of shared consumption (as described above). If this happens within the same product/service system, it is known as "direct rebound effect". Otherwise, if saved time and/or money are spent on other consumption, this is an indirect rebound effect. Rebound effects can compensate or even overcompensate for the positive impacts of sharing and can lead to additional resources taken from the environment. It has even been argued that "the overall effects of sharing economy platforms may be small due to rebound effects." [51, p. 6].

4.1.5 Degradation Effect. The potential increase in service life efficiency can be counteracted by resources' faster degradation, which is a negative consequence of shared use. As pointed out by Weber [50], the shared use of a product usually degrades it faster. Faster degradation by intensified wear and tear can reduce or even reverse the optimization effect of sharing, which seems to be a frequent problem in $\mathrm{B} 2 \mathrm{C}$ sharing (invested resource, commercial provider). In an analysis of an e-scooter sharing scheme [59], it was observed that the average lifespan of a scooter was only 28.8 days. The study also found that around 4 per cent of the initial-cohort scooters disappeared the same day they went into service (a lifespan of " 0 " days). In an LCA study on shared dockless e-scooters, Hollingsworth et al. [60] found that without efforts to increase scooters' lifetime and modify distribution, collection, use and charging strategies, the integration of e-scooter sharing schemes in urban transportation systems can even exacerbate emissions and environmental impacts. In addition, it is highly plausible that people treat products they do not own with less care [61]. Practices of low care for shared things can lead to negative environmental impacts by speeding up resource inflows and waste outflows [62]. It is obvious that socio-economic aspects of sharing schemes, such as the anonymity of the sharing community, cultural contexts, the type of provider (individual or business), and the for-profit or notfor-profit distinction play a significant role in the degradation effect (see also Section 4.2).

Shorter lifetime corresponds to higher replacement costs [50] and more resources that flow into the system per time. Although this problem can be approached via pricing models which set effective prices for sharing (i.e. prices that disincentivise carless use) and to include activities that extend the service-life of the products (such as maintenance and repair) [50], the importance of product design [63] can hardly be underestimated with respect to sustainable 'shareability' of products in the DSE [62].

\subsection{Socio-economic Impacts}

For each of the 5 categories of platforms that we outlined in the methodology section (see Figure 1), we identify the aspects relevant for sustainability from a socio-economic perspective.

4.2.1 Category 1: Not-for-profit C2C Sharing Model. These platforms most resonate with the traditional notion of sharing. They focus on promoting social values rather than seeking economic benefits. Such business models can belong to mission-driven platforms which intermediate between peer consumers to promote the common good [20]. They may pursue missions to transform the economy and to engender new practices in sustainable consumption and social relationships. They aim to reduce waste, cut out supply chain intermediaries, or build social connections among distributed strangers or enhance the connections among neighbors in a locality [20]. Such models are normally associated with positive moral and social connotations. These impacts of sharing are viewed in the contexts of social mission [20], social innovation [64], and social movement [65].

4.2.2 Category 2: Capital-based For-profit C2C Sharing Model. Platforms of this type monetize resources. They provide open and (extremely) easy-to-participate networks for their users. In many cases (if not always), the entry barriers for providers are considerably lower compared to the traditional counterparts in the formal economy offering similar services. Having possession of an asset to offer, a digital end-user device, downloading the app, and agreeing to a platform's terms and conditions would normally suffice to act as a resource provider in the system. With respect to economic benefit and income, the DSE has created a positive effect by moving towards welfare enhancement [51]. However, from a provider perspective, the DSE is said to be basically acting in favor of those who already have assets to share with others; it is argued that it would exclude around $80 \%$ of those at the bottom of the income distribution $[51,66]$.

On the one hand, platforms of this type are being criticized because of enjoying a competitive advantage over the formal market by avoiding local restrictions and formal regulations on entry and licensing requirements [67]. On the other hand, some platforms have raised controversies about inequality mainly with respect to dependency on possessing an asset, classification of consumers and providers (in terms of race hierarchies) and classbased or person-to-person discrimination [43]. The last two points 
have been mainly discussed in studies on the prevalence of digital discrimination occurring in capital-based platforms like Airbnb [68-69]. Edelman and Luca [69] found that Airbnb's effort to facilitate trust by providing personal profiles and pictures of accommodation providers may facilitate discrimination based on the providers' race, gender, age, or aspects of appearance. Therefore, alongside direct economic impacts such as economic empowerment and generating extra income, platforms can reveal and amplify discrimination, racial disadvantages, and exclusionary behavior in the choice of sharing partners [51] as negative social impacts.

In the context of social relations and social ties, some studies reported users' satisfaction with the relations they develop and with platforms helping them constructing new social networks with people they otherwise would never have met [51]. However, some authors point to the risk that sharing platforms may harm preexisting social cohesion: Since platforms economize private assets, people may prefer to earn money from what was normally available to family and friends for free in the past $[51,70]$.

4.2.3 Category 3: Labor-Based For-Profit C2C Sharing Model. The labor-based sharing model, also known as "the gig economy" [71], creates informal labor markets with low entry barriers. A prominent example is Uber, where the providers and the receivers are peers, activating existing resources for an economic motivation. Gig workers are usually classified as independent contractors who are not eligible for most employee benefits and labor protections [52]. The market for 'gig' workers can create issues related to the promotion of tax avoidance and erosion of workers' rights [14]. Owing to legal uncertainty with regard to tax legislation and enforcement as well as lack of comprehensive rules in respect of labor law issues, tax treatment differs among different platforms [72]. This can lead to a situation where sharing platforms gain a competitive advantage against their competitors outside the DSE, hence creating unfair situation for workers in the non-sharing economy [72].

With regard to underpayment and low wages, the DSE has been labeled as "share-the-scraps economy" where most of the profits will go to the platform owners and the scraps go to the workers [73].

4.2.4 Category 4: Not-for-profit B2C Sharing Model. These platforms belong to the 'commoners' type of BM (such as FabLab and iFixIt), as defined by Acquier and colleagues [20], that create and provide free access to public goods with the aim to make resource pooling available to the greatest number. They promote a normative idea based on alternative and non-market values, such as open-knowledge, do it yourself(DIY), and decentralizing resources with the aim to improve free contribution and free access [20]. The BM of such initiatives enables value creation by contributors' voluntary work. One could think of these platforms as materialresource-based counterparts of Wikipedia.

4.2.5 Category 5: For-profit B2C Sharing Model. In regard to this category, it is observed that its BMs are based on consumers' engagement in the process of service provision. For example,
Zipcar requires its users to return the cars clean and not to leave them with low fuel; otherwise, fines may incur. Such consumer engagement can promote a collective sense of responsibility within the community. For the business, this will eliminate the need for hired staff for the tasks that can be externalised to the consumers.

Competition between $\mathrm{B} 2 \mathrm{C}$ platforms and their counterparts in non-sharing markets is another relevant impact. This impact is associated with platforms in Categories 2 and 3 as well. There is a great deal of critisism against profit-oriented sharing models (be it $\mathrm{C} 2 \mathrm{C}$ or $\mathrm{B} 2 \mathrm{C}$ ), arguing that they tend to create quasi-monopolistic market structures that exploit regulatory voids [20]. These models have been accused of using sophisticated algorithms that externalize social costs, responsibility, and the risks associated with uncertainty and economic fluctuations to platform users [20,74]. They have been also criticised for performing forms of "pseudosharing that masquerade as communal sharing" [70] based on business relationships instead of promoting social exchanges and shared value creation [20].

Profit-oriented sharing models can have implications for businesses in the formal economy and their workers, most importantly in the context of competition with incumbents and established industries. Because of the affordability and increasing popularity of sharing services, pipeline businesses and their workers may be likely to experience lower earnings [51].

The impacts of the DSE on established industries come with evidence in cases. For example, the market for car rentals have faced increased competition due to the rise of car-sharing platforms. According to a report, the US total rental-car fleet dropped 5\% year-over-year due to the operation of riding service platforms [75]. In the hospitality area, there could be effects on the supply and price of housing in places where home sharing is more widespread and popular because this could escalate rents for people seeking long-term residency [51]. The case of the city Barcelona provides evidence of this effect [76].

Such impacts are usually referred to as the disruptive effect of sharing platforms on established industries [77]. While impacts across industries are not even [51], the impacts of one particular platform may also be dependent on geographic, cultural and political context.

\section{RESULTS AND DISCUSSION}

We identified sustainability-related aspects of sharing BMs and the resulting potential positive and negative impacts of the sharing platforms using these BMs. It depends on the specific context in which a sharing system is placed (or emerges) to what extent these impacts materialize. We, therefore, speak of opportunities (= potential impacts that will be seen as benefits) and risks (= potential impacts that will be seen as disadvantages) of the DSE from a sustainability viewpoint.

Table 1 summarizes the opportunities and risks of $\mathrm{C} 2 \mathrm{C}$ and $\mathrm{B} 2 \mathrm{C}$ sharing models for sustainability. 


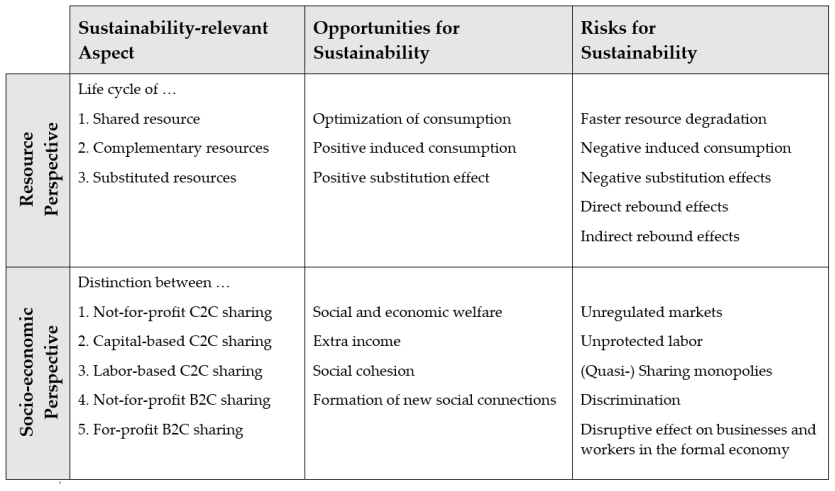

Table 1. Opportunities and risks of the $\mathrm{C} 2 \mathrm{C}$ and $\mathrm{B} 2 \mathrm{C}$ digital sharing business models for sustainability from the resource and socio-economic perspectives.

Regarding the opportunities and risks of sharing BMs for sustainability, several points can be raised. From a resource perspective, platform-based sharing practices should be checked for both positive and negative effects on resource consumption and resource inflow [39, 62]:

- With regard to optimization effects, the basic objective function in a sharing system should be the number of functional units delivered per life-cycle-wide resource use of all product/service systems involved. This function increases by shared use but is also driven down by the faster degradation of resources that can take place especially in the context of commercial sharing models (B2C).

- It is important to explore to what extent the sustainability impacts of the material assets - calculated per functional unit (service unit) provided - are smaller than in the non-sharing consumption patterns they replace.

- It may happen that the material, energy, time and cost savings stimulate the demand for the service to an extent that counterbalances for the theoretical savings (direct rebound) or that saved money and time are spent for other consumption (indirect rebound). The net effect of sharing on resource consumption then depends on the extent of the rebound effects in the specific case.

- Not only the shared resource itself, but also coupled consumption activities should be taken into account for a thorough assessment. If all resources needed to produce the final service are considered, optimizing the use of one of them at the cost of increasing the use of others may not necessarily contribute to sustainability.

- The effects of substituted consumptions can have different implications for sustainability depending on whether the new consumption choice(s) would substitute for higher- or lowerimpact options.

- Investments in additional assets for profitable sharing may indicate strong rebound effects. For the investments to be profitable, demand will have to increase. Although commercial platforms would welcome this as the growth of their business, from a sustainability perspective, increasing demand may lead to faster resource depletion.

From a socio-economic perspective, it is important to address the following relevant questions [1]:
- To what extent will the platform contribute to opportunities for everyone to participate in a given market or community and to fair distribution?

- Will the people who provide access to resources in digital sharing systems be in a social position that is better than before (e.g., regarding access to sharing markets, protected labor conditions, protected self-development, etc.)?

- Will people who receive access to resources in digital sharing systems be in a social position that is better than before (e.g., regarding access to resources, consumer rights, etc.)?

- Can the established sharing practices be expected to support the development of social norms, institutions, and policies that are conducive to sustainable development?

Furthermore, the following questions addressing the relationship of sharing systems to their surrounding systems may complete the picture:

- To what extent can sharing platforms affect the businesses and their workers in the formal economy?

- To what extent can sharing platforms affect people's life in the local ecological and social environment in which they operate?

\section{CONCLUSION AND OUTLOOK}

Digitally enabled sharing creates a broad spectrum of opportunities and risks when viewed through the lens of sustainability. Changes in consumption patterns occur by enabling and promoting shared use as a new mode of consumption; new social practices can lead to persisting changes in socio-economic structures. Because of the popularity of services offered by sharing platforms, there has been a remarkable shift of consumption patterns. It is important to develop an unbiased and differentiated understanding of whether and how these sharing models can promote or hinder sustainability.

From a resource perspective, a classification of ICT impacts on sustainability can be used to describe how a resource (and its complementary resources) is better utilized in a sharing system, whereby the whole life cycle of all the induced and substituted resource consumption should be taken into account. It can also further address broader impacts such as rebound effects. Faster degradation is an issue that may partially or fully offset the optimiztion effects, in particular in for-profit sharing models.

Different sharing systems may have different socio-economic implications in the sense of how sharing practices may affect participants' social life and economic standing. With respect to the focus of the present paper on $\mathrm{C} 2 \mathrm{C}$ and $\mathrm{B} 2 \mathrm{C}$ business models, we found it a rewarding attempt to classify sharing platforms in a way that could manifest or emphasize differences in their socioeconomic impacts based on their BM type. From a social perspective, it is important to see whether participants in sharing, particularly providers and receivers in peer networks, would attain a better social and economic position in terms of equal access to markets, participation in social life, labor conditions and opportunities for protected work, and a decent life. Relevant considerations could address equal opportunities for everyone in the market. 
The conceptual and qualitative analysis presented here could be further developed to provide a guideline for designing and implementing sustainable BMs in the digital sharing economy. The analysis can also assist in envisioning possible regulatory requirements for directing sharing practices towards favorable sustainability performances. Future work may also attempt to operationalize the aspects described in our analysis to create an empirical methodology to assess the impacts of sharing BMs. In the best case, such a method could help regulating platform activities, enhancing social life and supporting fair distribution of opportunities to participate in sharing communities.

\section{REFERENCES}

[1] Maria J. Pouri and Lorenz M. Hilty. 2018. Conceptualizing the Digital Sharing Economy in the Context of Sustainability. Sustainability 10, 12 (2018), 4453. DOI:http://dx.doi.org/10.3390/su10124453

[2] Eliane Bucher, Christian Fieseler, and Christoph Lutz. 2016. Whats mine is yours (for a nominal fee) - Exploring the spectrum of utilitarian to altruistic motives for Internet-mediated sharing. Computers in Human Behavior 62 (2016), 316-326. DOI:http://dx.doi.org/10.1016/j.chb.2016.04.002

[3] Waqar Nadeem, Mari Juntunen, Nick Hajli, and Mina Tajvidi. 2019. The Role of Ethical Perceptions in Consumers' Participation and Value Co-creation on Sharing Economy Platforms. Journal of Business Ethics (2019). DOI:http://dx.doi.org/10.1007/s10551-019-04314-5

[4] Jochen Wirtz, Kevin Kam Fung So, Makarand Amrish Mody, Stephanie Q. Liu, and Haeeun Helen Chun. 2019. Platforms in the peer-to-peer sharing economy. Journal of Service Management 30, 4 (2019), 452-483. DOI:http://dx.doi.org/10.1108/josm-11-2018-0369

[5] Marshall W. van Astyne, Geoffrey G. Parker, Sangeet Paul Choudary. 2016. Pipelines, platforms, and the new rules of strategy. Harvard business review, 94 , 4 (2016), 54-62.

[6] Juho Hamari, Mimmi Sjöklint, and Antti Ukkonen. 2015. The sharing economy: Why people participate in collaborative consumption. Journal of the Association for Information Science and Technology 67, 9 (February 2015), 2047-2059. DOI:http://dx.doi.org/10.1002/asi.23552

[7] Lizzie Richardson. 2015. Performing the sharing economy. Geoforum 67 (2015), 121-129. DOI:http://dx.doi.org/10.1016/j.geoforum.2015.11.004

[8] Subhajit Das. 2017. Catching the sharing economy wave: Disney World and the delight of discovery. (September 2017). Retrieved April 30, 2020 from https://www.christenseninstitute.org/blog/catching-sharing-economy-wavedisney-world-delight-discovery/

[9] Ronaldo C. Parente, José-Mauricio G. Geleilate, and Ke Rong. 2018. The Sharing Economy Globalization Phenomenon: A Research Agenda. Journal of International Management 24, 1 (2018), 52-64. DOI:http://dx.doi.org/10.1016/j.intman.2017.10.001

[10] Judd Cramer and Alan B. Krueger. 2016. Disruptive Change in the Taxi Business: The Case of Uber. American Economic Review 106, 5 (2016), 177 182. DOI:http://dx.doi.org/10.1257/aer.p20161002

[11] Georgios Zervas, Davide Proserpio, and John W. Byers. 2017. The Rise of the Sharing Economy: Estimating the Impact of Airbnb on the Hotel Industry. Journal of Marketing Research 54, 5 (2017), 687-705. DOI:http://dx.doi.org/10.1509/jmr.15.0204

[12] Damien Demailly and Anne-Sophie Novel. 2014. The sharing economy: make it sustainable. Studies, 3(14.1)

[13] Harald Heinrichs. 2013. Sharing Economy: A Potential New Pathway to Sustainability. GAIA - Ecological Perspectives for Science and Society 22, 4 (2013), 228-231. DOI:http://dx.doi.org/10.14512/gaia.22.4.5
[14] Chris J. Martin. 2016. The sharing economy: A pathway to sustainability or a nightmarish form of neoliberal capitalism? Ecological Economics 121 (2016), 149-159. DOI:http://dx.doi.org/10.1016/j.ecolecon.2015.11.027

[15] Maria J. Pouri and Lorenz M. Hilty. 2020. The Digital Sharing Economy: A Confluence of Technical and Social Sharing. Submitted for publication.

[16] World Commission on Environment and Development (WCED). 1987. Our Common Future. Oxford University Press: Oxford, UK.

[17] Kate Raworth. 2017. Doughnut economics: seven ways to think like a 21stcentury economist. Chelsea Green Publishing.

[18] Thomas Burkhart, Julian Krumeich, Dirk Werth, and Peter Loos. 2011. Analyzing the business model concept - a comprehensive classification of literature. In Proceedings of the 32nd International Conference on Information Systems, $p p$. $1-19$ https://aisel.aisnet.org/icis2011/proceedings/generaltopics/12

[19] Muhammad Yunus, Bertrand Moingeon, and Laurence Lehmann-Ortega. 2010 Building Social Business Models: Lessons from the Grameen Experience. Long Range Planning 43, 2-3 (2010), 308-325. DOI:http://dx.doi.org/10.1016/j.lrp.2009.12.005

[20] Aurélien Acquier, Valentina Carbone, and David Massé. 2019. How to Create Value(s) in the Sharing Economy: Business Models, Scalability, and Sustainability. Technology Innovation Management Review 9, 2 (2019), 5-24. DOI:http://dx.doi.org/10.22215/timreview/1215

[21] Oliver Laasch. 2018. Beyond the purely commercial business model: Organizational value logics and the heterogeneity of sustainability business models. Long Range Planning 51, 1 (2018), 158-183. DOI:http://dx.doi.org/10.1016/j.lrp.2017.09.002

[22] Chris J. Martin, Paul Upham, and Leslie Budd. 2015. Commercial orientation in grassroots social innovation: Insights from the sharing economy. Ecological Economics $118 \quad$ (2015), 240-251. DOI:http://dx.doi.org/10.1016/j.ecolecon.2015.08.001

[23] Steve Evans, Doroteya Vladimirova, Maria Holgado, Kirsten Van Fossen, Miying Yang, Elisabete A. Silva, and Claire Y. Barlow1. 2017. Business Model Innovation for Sustainability: Towards a Unified Perspective for Creation of Sustainable Business Models. Business Strategy and the Environment 26, 5 (May 2017), 597-608. DOI:http://dx.doi.org/10.1002/bse.1939

[24] Jad Asswad, Georg Hake, and Jorge Marx Gómez. 2016. The Obstacles of Sustainable Business Model Innovations. In proceedings of International Conference on Information Resources Management (CONF-IRM). CONF-IRM 2016 Proceedings. Paper 11. http://aisel.aisnet.org/confirm2016/11

[25] Frank Boons and Florian Lüdeke-Freund. 2013. Business models for sustainable innovation: state-of-the-art and steps towards a research agenda. Journal of $\begin{array}{llll}\text { Cleaner } & \text { Production } & 45 & \text { (2013), }\end{array}$ DOI:http://dx.doi.org/10.1016/j.jclepro.2012.07.007

[26] Francesca Ciulli and Ans Kolk. 2019. Incumbents and business model innovation for the sharing economy: Implications for sustainability. Journal of Cleaner Production $214 \quad$ (2019), 995-1010. DOI:http://dx.doi.org/10.1016/j.jclepro.2018.12.295

[27] Jeff Hong. 2018. Rise of the Sharing Economy and the Future of Travel and Tourism Industry. Journal of Business and Hotel Management 07, 02 (2018). DOI:http://dx.doi.org/10.4172/2169-0286.1000180

[28] Zhenfeng Liu, Jian Feng, and Jinfeng Wang. 2019. Effects of the Sharing Economy on Sequential Innovation Products. Complexity 2019 (2019), 1-18. DOI:http://dx.doi.org/10.1155/2019/3089641

[29] Cristiano Codagnone, Federico Biagi, and Fabienne Abadie. 2016. The Passions and the Interests: Unpacking the Sharing Economy. SSRN Electronic Journal (2016). DOI:http://dx.doi.org/10.2139/ssrn.2793901

[30] Catalin Mihail Barbu, Dorian Laurentiu Florea, Radu Florin Ogarca, and Mihai Constantin Razvan Barbu. 2018. From Ownership to Access: How the Sharing Economy is Changing the Consumer Behavior. www. amfiteatrueconomic.ro 20, 48 (2018), 373. DOI:http://dx.doi.org/10.24818/ea/2018/48/373

[31] Elaine Coventry. Here's how consumption will change over the next decade. Retrieved May 1, 2020 from https://www.weforum.org/agenda/2018/01/howconsumption-will-change-over-next-decade/ 
[32] Fleura Bardhi and Giana M. Eckhardt. 2012. Access-Based Consumption: The Case of Car Sharing: Table 1. Journal of Consumer Research 39, 4 (January 2012), 881-898. DOI:http://dx.doi.org/10.1086/666376

[33] Joan Torrent-Sellens. 2020. Collaborative Behavior and the Sharing Economy: Pan-European Evidence for a New Economic Approach. Strategy and Behaviors in the Digital Economy (April 2020). DOI:http://dx.doi.org/10.5772/intechopen.83608

[34] Tingting Christina Zhang, Huimin Gu, and Melissa Farboudi Jahromi. 2019. What makes the sharing economy successful? An empirical examination of competitive customer value propositions. Computers in Human Behavior 95 (2019), 275-283. DOI:http://dx.doi.org/10.1016/j.chb.2018.03.019

[35] Hung-Tai Tsou, Ja-Shen Chen, Yunhsin Chou, and Tzu-Wen Chen. 2019. Sharing Economy Service Experience and Its Effects on Behavioral Intention. Sustainability 11, 18 (2019), 5050. DOI:http://dx.doi.org/10.3390/su11185050

[36] Lars Böcker and Toon Meelen. 2017. Sharing for people, planet or profit? Analysing motivations for intended sharing economy participation. Environmental Innovation and Societal Transitions 23 (2017), 28-39. DOI:http://dx.doi.org/10.1016/j.eist.2016.09.004

[37] David J. Teece. 2010. Business Models, Business Strategy and Innovation. Long $\begin{array}{lllll}\text { Range } & \text { Planning } & 43, & 2-3 & \text { (2010), }\end{array}$ DOI:http://dx.doi.org/10.1016/j.lrp.2009.07.003

[38] Maria J. Pouri and Lorenz M. Hilty. 2020. A Typology of Digital Sharing Business Models: A Design Science Research Approach. 15th International Conference on Design Science Research in Information Systems and Technology (DESRIST) 2020. Accepted for publication.

[39] Maria J. Pouri and Lorenz M. Hilty. 2018. ICT-Enabled Sharing Economy and Environmental Sustainability-A Resource-Oriented Approach. Progress in IS Advances and New Trends in Environmental Informatics (2018), 53-65. DOI:http://dx.doi.org/10.1007/978-3-319-99654-7_4

[40] Lorenz M. Hilty and Bernard Aebischer. 2014. ICT for Sustainability: An Emerging Research Field. Advances in Intelligent Systems and Computing ICT Innovations for Sustainability (July 2014), 3-36. DOI:http://dx.doi.org/10.1007/978-3-319-09228-7_1

[41] José G. Vargas-Hernández. 2020. Uber's Strategy as a Competitive Business Model of Sharing Economy. In Sharing Economy and the Impact of Collaborative Consumption. IGI (2020), 97-115. DOI:http://dx.doi.org/10.4018/978-1-5225-9928-9.ch006

[42] Makhmoor Bashir and Rajesh Verma. 2016. Airbnb disruptive business model innovation: Assessing the impact on hotel industry. International Journal of Applied Business and Economic Research, 14(4), pp.2595-2604.

[43] Juliet B. Schor and William Attwood-Charles. 2017. The "sharing" economy: labor, inequality, and social connection on for-profit platforms. Sociology Compass 11, 8 (2017). DOI:http://dx.doi.org/10.1111/soc4.12493

[44] Raza Hasan and Mehdi Birgach. 2016. Critical success factors behind the sustainability of the Sharing Economy. 2016 IEEE 14th International Conference on Software Engineering Research, Management and Applications (SERA) (2016). DOI:http://dx.doi.org/10.1109/sera.2016.7516158

[45] Tom Slee. 2016. Whats Yours Is Mine. OR Books (November 2016). DOI:http://dx.doi.org/10.2307/j.ctt1bkm65n

[46] Asta Daunorienè, Aura Drakšaite, Vytautas Snieška, and Gitana Valodkienė. 2015. Evaluating Sustainability of Sharing Economy Business Models. Procedia - Social and Behavioral Sciences 213 (2015), 836-841. DOI:http://dx.doi.org/10.1016/j.sbspro.2015.11.486

[47] Lorenz M. Hilty and Wolfgagn Lohmann. 2013. An Annotated Bibliography of Conceptual Frameworks in ICT for Sustainability. In: ICT4S - First International Conference on Information and Communication Technologies for Sustainability, Zürich, 12 February 2013 - 14 February 2013, 288-300.

[48] Frans Berkhout and Julia Hertin. 2001. Impacts of information and communication technologies on environmental sustainability: speculations and evidence. Report to the OECD (2001). Retrieved 02 May, 2020 from http://www.oecd.org/dataoecd/4/6/1897156.pdf

[49] Mario Dompke, Justus von Geibler, Wolf Göhring, Melanie Herget, Lorenz M. Hilty, Ralf Isenmann, Michael Kuhndt, Stefan Naumann, Dietlinde Quack, Eberhard K. Seifert. 2004. Memorandum Nachhaltige Informationsgesellschaft. Fraunhofer IRB, Stuttgart (2004). ISBN: 3-8167-6446-0.
[50] Thomas A. Weber. 2018. The Dynamics of Asset Sharing and Private Use. In Proceedings of the 51st Annual Hawaii International Conference on System Sciences (HICSS), Waikoloa Village, HI, USA, 3-6 January 2018; pp. 52055211.

[51] Koen Frenken and Juliet Schor. 2017. Putting the sharing economy into perspective. Environmental Innovation and Societal Transitions 23 (2017), 3 10. DOI:http://dx.doi.org/10.1016/j.eist.2017.01.003

[52] Andrei Hagiu and Julian Wright. 2019. The status of workers and platforms in the sharing economy. Journal of Economics \& Management Strategy 28, (2019), 97-108. DOI:http://dx.doi.org/10.1111/jems.12299

[53] Maria J. Pouri and Lorenz M. Hilty. 2021. A Causal Model for Explaining the Sustainability Impacts of Consumption in the Digital Sharing Economy. 2021 International Conference on Resource Sustainability, 20-22 July, Dublin, Irland. Accepted for publication.

[54] Ivana Pais. 2019. Digital Platforms and the Transformations in the Division of Labor. Handbook of Labor, Human Resources and Population Economics (2019), 1-16. DOI:http://dx.doi.org/10.1007/978-3-319-57365-6_16-1

[55] Rachel Botsman. Transcript of "The case for collaborative consumption". $\begin{array}{llll}\text { Retrieved } & \text { May } & 2 & 2020\end{array}$ https://www.ted.com/talks/rachel_botsman_the_case_for_collaborative_consu $\mathrm{mption} /$ transcript?language $=$ en

[56] Gregory D. Erhardt, Sneha Roy, Drew Cooper, Bhargava Sana, Mei Chen, and Joe Castiglione. 2019. Do transportation network companies decrease or increase congestion? Science Advances 5, 5 (2019). DOI:http://dx.doi.org/10.1126/sciadv.aau2670

[57] Bruce Schaller. 2017. Unsustainable? The growth of app-based ride services and traffic, travel and the future of New York City. Schaller Consulting. (2017). $\begin{array}{llll}\text { Retrieved } & \text { May } & 2020 & \text { 2, }\end{array}$ http://schallerconsult.com/rideservices/unsustainable.htm

[58] Elliot W. Martin and Susan A. Shaheen. 2011. Greenhouse Gas Emission Impacts of Carsharing in North America. IEEE Transactions on Intelligent Transportation Systems 12, 4 (2011), 1074-1086. DOI:http://dx.doi.org/10.1109/tits.2011.2158539

[59] Alison Griswold. 2019. Shared scooters don't last long. (March 2019). Retrieved May 2, 2020 from https://qz.com/1561654/how-long-does-a-scooter-last-lessthan-a-month-louisville-data-suggests/

[60] Joseph Hollingsworth, Brenna Copeland, and Jeremiah X. Johnson. 2019. Are e-scooters polluters? The environmental impacts of shared dockless electric scooters. Environmental Research Letters 14, 8 (February 2019), 084031. DOI:http://dx.doi.org/10.1088/1748-9326/ab2da8

[61] Arnold Tukker. 2015. Product services for a resource-efficient and circular economy - a review. Journal of Cleaner Production 97 (2015), 76-91. DOI:http://dx.doi.org/10.1016/j.jclepro.2013.11.049

[62] Maria J. Pouri and Lorenz M. Hilty. 2019. Digitally Enabled Sharing and the Circular Economy: Towards a Framework for Sustainability Assessment Progress in IS Advances and New Trends in Environmental Informatics (2019), 105-116. DOI:http://dx.doi.org/10.1007/978-3-030-30862-9_8

[63] Nancy M.P. Bocken, Ingrid De Pauw, Conny Bakker, and Bram Van Der Grinten. 2016. Product design and business model strategies for a circular economy. Journal of Industrial and Production Engineering 33, 5 (2016), 308 320. DOI:http://dx.doi.org/10.1080/21681015.2016.1172124

[64] Aurélien Acquier and Valentina Carbone. 2018. Sharing economy and social innovation. The Cambridge Handbook of the Sharing Economy and Law, pp.5164.

[65] Stefan Kirchner and Elke Schüßler. 2020. Regulating the Sharing Economy: A Field Perspective. Theorizing the Sharing Economy: Variety and Trajectories of New Forms of Organizing Research in the Sociology of Organizations (October 2020), 215-236. DOI:http://dx.doi.org/10.1108/s0733-558x20200000066010

[66] Juliet B. Schor. 2017. Does the sharing economy increase inequality within the eighty percent?: findings from a qualitative study of platform providers. Cambridge Journal of Regions, Economy and Society 10, 2 (October 2017), 263-279. DOI:http://dx.doi.org/10.1093/cjres/rsw047

[67] Chiara Farronato and Jonathan Levin. The sharing economy - Credit Suisse. Retrieved May 7, 2020 from https://www.credit- 
suisse.com/media/assets/corporate/docs/news-andexpertise/articles/2016/07/global-investor-2-15-en.pdf

[68] Greg Harman. 2014. The sharing economy is not as open as you might think. (November 2014). Retrieved May 7, 2020 from https://www.theguardian.com/sustainable-business/2014/nov/12/algorithmsrace-discrimination-uber-lyft-airbnb-peer

[69] Benjamin Edelman and Michael Luca. 2014. Edelman, Benjamin G., Luca, and Michael. 2014. Digital Discrimination: The Case of Airbnb.com. (January 2014). Retrieved May 7, 2020 from https://papers.ssrn.com/sol3/papers.cfm?abstract_id=2377353

[70] Russell Belk. 2014. Sharing Versus Pseudo-Sharing in Web 2.0. The $\begin{array}{lllll}\text { Anthropologist } & 18, & 1 & \text { (2014), } & \end{array}$ DOI:http://dx.doi.org/10.1080/09720073.2014.11891518

[71] Valerio De Stefano. 2015. The Rise of the Just-in-Time Workforce: On-Demand Work, Crowd Work and Labour Protection in the Gig-Economy. SSRN Electronic Journal (2015). DOI:http://dx.doi.org/10.2139/ssrn.2682602.

[72] Katerina Pantazatou. 2017. Taxation of the Sharing Economy in the European Union. SSRN Electronic Journal (2017) DOI:http://dx.doi.org/10.2139/ssrn.3091281

[73] Kibum Kim, Chulwoo Baek, and Jeong-Dong Lee. 2018. Creative destruction of the sharing economy in action: The case of Uber. Transportation Research Part A: Policy and Practice 110 (2018), 118-127. DOI:http://dx.doi.org/10.1016/j.tra.2018.01.014

[74] Gerald Friedman. 2014. Workers without employers: shadow corporations and the rise of the gig economy. Review of Keynesian Economics 2, 2 (2014), 171188. DOI:http://dx.doi.org/10.4337/roke.2014.02.03

[75] Wolf Richter. 2018. Numbers are in: Uber, Lyft v. Rental Cars \& Taxis in the US in Q2. (July 2018). Retrieved May 7, 2020 from https://wolfstreet.com/2018/07/29/the-numbers-are-in-uber-lyft-versus-rentalcars-and-taxis-in-the-us-in-q2/

[76] Stephen Burgen. 2020. Soaring rents and noisy parties: how Airbnb is forcing out Barcelona locals. (February 2020). Retrieved May 7, 2020 from https://www.theguardian.com/technology/2020/feb/20/soaring-rents-andnoisy-parties-how-airbnb-is-forcing-out-barcelona-locals

[77] Daniel Guttentag (2015) Airbnb: disruptive innovation and the rise of an informal tourism accommodation sector, Current Issues in Tourism, 18:12, 1192-1217, DOI:10.1080/13683500.2013.827159 